\title{
Categoria
}

Relato de Experiência

Titulo do Trabalho

\section{PROGRAMA OLHAR AMBIENTAL}

\author{
Nome do Autor (a) Principal
}

\section{Luana Ferreira Pires}

Nome (s) do Coautor (a) (s)

\section{Jaqueline Caleiras Magalhães; Renata Borini Marcondes e Santos}

Nome (s) do Orientador (a) (s)

\section{Angélica Góis Morales; Cristiane Hengler Corrêa Bernardo; Renato Dias Baptista}

Instituição ou Empresa

\author{
Univ. Estadual Paulista (UNESP, Câmpus de Tupã) \\ Instituição (s) de Fomento
}

\section{Pró-Reitoria de Extensão - PROEX}

\author{
E-mail de contato \\ olhar_ambiental@hotmail.com
}

RESUMO: Atualmente, a questão ambiental torna-se emergente em todos os segmentos da sociedade, inclusive nas formações acadêmicas e, as tecnologias voltadas ao sistema comunicacional, cada vez mais vêm contribuindo na disseminação de temas socioambientais, a fim de socializar, esclarecer e divulgar essa temática. Nesse contexto, este trabalho tem como objetivo geral elaborar o Programa Ambiental e toda sua configuração a fim de promover a divulgação de iniciativas ambientais desenvolvidas na região de Tupã, estado de São Paulo. Para tanto, adotou-se como encaminhamento metodológico durante 0 desenvolvimento do programa a pesquisa-ação, responsável por potencializar a participação de todos integrantes da equipe do programa, o que exigiu a realização de oficinas de formação que abordassem as atividades futuramente exercidas pelos mesmos. O "Programa Olhar Ambiental", composto por docentes e acadêmicos da UNESP, Câmpus de Tupã, em parceria com a equipe da TV Universitária (Canal 30), bem como resultado do projeto de extensão, caracteriza-se por suas vertentes educativa, social, científica e 
técnica, que dentre outras contribuições, permite democratizar os conhecimentos na área ambiental, alcançar diferentes públicos e contextualizar o impacto ambiental com as diferentes esferas sociais.

Palavras-chave: Programa Olhar Ambiental. Comunicação. Televisão.

\section{INTRODUÇÃO}

Há vários anos a televisão deixou de ser apenas um meio de comunicação para assumir a posição de mídia, em função de sua facilidade de aquisição à maior parte da população e, sua inegável capacidade de alcançar diferentes públicos através da exibição de programas que despertam o interesse desses telespectadores (TEODORO et al., 2010).

Embora, ainda sejam muito questionados os caráteres educativo e cultural dos conteúdos veiculados nessa mídia, a televisão, por muitas vezes, é entendida como mediadora de debates, origem de análises críticas, formadora de cidadãos (BARROS, 2010). Como Curado (2002) afirma, as noticias veiculadas pela TV devem ter sua origem numa prática reflexiva e continuada. $E$, é dentro de tal encaminhamento que as apresentações e discussões na área ambiental devem provocar nos telespectadores: a disseminação e, principalmente a reflexão e, consequentemente, a crítica.

Para tanto, a transmissão de informações referentes aos assuntos em voga na sociedade é de grande relevância e, dentre tantos temas, a questão ambiental aparece como uma discussão emergente. O cenário ambiental catastrófico que se encontra o planeta é reflexo da utilização inadequada dos recursos naturais ou ausência de práticas visando a preservação e conservação dos mesmos, tornando necessária que a discussão acerca dos fenômenos decorrentes no meio ambiente esteja sob os holofotes, e isso inclui a mídia televisiva.

Portanto, os assuntos ambientais merecem destaque especial e ainda é necessário voltar-se para espaços que possam tratar da questão e também de suas problemáticas de maneira mais crítica e sistêmica, e principalmente, como reforça Boff 
(1999), que a dimensão ambiental possa exigir uma ética da responsabilidade e do cuidado.

Com a expectativa de informar a população e incitar debates em busca de soluções para os problemas naturais, bem como promover a conscientização social visando a ampliação das práticas sustentáveis, a televisão tem reservado um espaço em sua programação, porém o meio ambiente nessa mídia ainda é comumente associado a fauna e flora apenas, deixando de lado impactos promovidos por ele em outros âmbitos da sociedade.

Considerando o contexto apresentado, surge um projeto de extensão na Universidade Estadual Paulista (UNESP), no Câmpus de Tupã intitulado "Programa Ambiental: difusão de conhecimentos locais e regionais", coordenado pela docente Prof. ${ }^{a}$ Dr. a Angélica Góis Morales e com a colaboração dos professores Cristiane Hengler Corrêa Bernardo e Renato Dias Baptista. Tal projeto nasce com o desejo de levar à sociedade, uma visão ambiental sob a ótica de diferentes segmentos sociais acerca das questões ambientais e, paralelamente, estimular os acadêmicos do curso de Administração, a participarem dessa discussão ambiental nos diversos segmentos uma formação profissional, já que terão a oportunidade de exercitar a redação e comunicação na execução desse programa.

\section{OBJETIVO GERAL}

Elaborar o Programa Ambiental e toda sua configuração a fim de promover a divulgação de iniciativas desenvolvidas na região de Tupã, estado de São Paulo na área ambiental.

\section{OBJETIVOS ESPECÍFICOS}

Os objetivos específicos para a criação do programa foram:

- Identificar instituições e pessoas que estão atuando na área ambiental, seja em âmbitos formais ou não formais para participarem do programa por meio de entrevistas e documentários; 
- Realizar reuniões esporádicas para planejamento do Programa Ambiental a ser exibido na Tv Universitária em parceria com o Campus da UNESP de Tupã, que serão definidos de forma conjunta desde nome, duração, cronograma e dinâmica do programa;

- Exercitar a escrita por meio dos roteiros de cada programa e a oralidade dos acadêmicos;

- Realizar pesquisa bibliográfica sobre a temática ambiental;

- Divulgar os trabalhos desenvolvidos por professores da Unidade da Unesp, do Campus de Tupã, que tenham ênfase ou interface com as questões ambientais, bem como de empresários e instituições da região;

- Realizar curso de extensão que atenda conhecimentos mínimos na área de comunicação para contribuir com a equipe de trabalho (UNESP e TV Universitária).

\section{METODOLOGIA}

O encaminhamento metodológico adotado durante todo o desenvolvimento do programa é a pesquisa-ação, pois potencializa o processo participativo, no qual todos os sujeitos são atores principais e contribuem de forma colaborativa. Sendo assim, desde a elaboração do programa de televisão até sua execução, a equipe responsável pelo projeto1, participou ativamente na escolha do logotipo, titulo do programa, seleção dos temas, construção das pautas, filmagem e edição.

Para tanto, foram realizados oficinas de formação para a equipe de trabalho que abrangeram a elaboração de roteiros de pauta e filmagem. Paralelamente a essas atividades de formação, a equipe realizou o aprofundamento sobre a temática ambiental, por meio de pesquisas bibliográficas área ambiental e comunicacional.

O acompanhamento de rotinas e atividades da equipe foi feito por meio de atas, relatos e observações participantes durante a execução das atividades que compõe 0 programa.

\footnotetext{
${ }^{1}$ A equipe é composta por docentes e alunos do curso de Administração da UNESP e também pelo cinegrafista Nelson Alves da TV Universitária, Canal 30 de Tupã, SP.
} 


\section{RESULTADO (S)}

O Programa ambiental deu inicio em março de 2012 e a partir das discussões geradas pelo grupo de estudo integrante ao projeto, chegou-se à escolha do nome do programa definido como "Olhar Ambiental". Esse nome veio ao encontro da concepção de um programa que pudesse trazer as várias opiniões de profissionais sob a perspectiva ambiental. Dessa forma, diante de tais reflexões coletivas, adota-se a frase "todo ponto de vista é a vista de um ponto" que é do BOFF (1998, p.9) que vem reforçar a ideia do programa. Outro ponto destacado pelo grupo foi abordagem sistêmica do meio ambiente que o programa deve ter, pois a questão ambiental deve abarcar não apenas os aspectos naturais, mas também sociais, culturais, políticos e econômicos.

A partir do nome e da logomarca que também retrata o propósito do programa ${ }^{2}$, decidiu-se em consenso entre todos participantes o plano de trabalho da equipe, como uma reunião ordinária semanalmente com as discussões dos assuntos contidos nos fichamentos redigidos pelos alunos, bem como as pautas mensais para as gravações.

Nesse caminho de pensar o programa Olhar Ambiental juntos, além de criar a parte televisiva, também foi elaborado o Blog Olhar Ambiental (programaolharambiental. blogspot.com.br), que serve como meio de comunicação entre os telespectadores e a equipe do Programa, contribuindo na discussão do assunto apresentado.

Quanto aos cursos de extensão, foram ministrados dois durante o primeiro semestre. São eles: "Produção Para Programas de Televisão" e curso de "Noções Básicas De Filmagem", em parceria com a UNESP e Tv Universitária, canal 30. Tais cursos tiveram o objetivo de aprimorar os conhecimentos no quesito de técnicas televisivas, como a construção de pautas e as técnicas de filmagem e edição. Além dos cursos, os integrantes do grupo também puderam se familiarizar com a técnica geral sobre gravações e edição do programa por meio da estrutura os equipamentos de edição na Tv Universitária, o que contribuiu para o desenvolvimento dos programas na mídia.

A primeira edição do Programa Olhar Ambiental foi ao ar no dia 05 de junho desse ano, com o conteúdo da exclusão das sacolas plásticas nos supermercados, que é fruto

\footnotetext{
${ }^{2}$ A logomarca é uma lupa que representa o "poder olhar" para as várias dimensões do meio ambiente, bem como as diversas interpretações da população sobre o assunto.
} 
da resolução SMA-15 do Estado de São Paulo com a opinião de vários profissionais da área e da população e, com a apresentação da equipe do projeto de extensão e sua concepção.

O cenário que o programa "Olhar Ambiental" utiliza é o ambiente externo, preferencialmente, cercado pela natureza, usando ambientes fechados apenas em entrevistas onde não haja outra possibilidade. Por isso, foge do modelo tradicional de telejornais e documentários, no qual as cabeças das matérias são apresentadas do estúdio, mesmo que as reportagens sejam no ambiente externo. O programa vem sendo apresentado mensalmente, com duração de 30 minutos e dividido por 02 blocos temáticos, no qual o primeiro divulga projetos da região na área ambiental e no segundo traz discussão de um tema atual e busca opinião de diversas pessoas e instituições.

Atualmente, o programa encontra-se na terceira edição e nas primeiras apresentações na mídia, já teve o reconhecimento pela população tupãense ao receber uma Moção da Câmara dos Vereadores.

Quanto aos aprendizados da equipe, contata-se por meio dos depoimentos dos alunos, que houve um desenvolvimento positivo no quesito desinibição, tanto em relação aos entrevistadores quanto aos pauteiros; conhecimentos básicos em filmagem e construção de textos, assim como aprimoramento de pesquisa para construção do programa e possibilidade de diálogo com profissionais que atuam, principalmente, na área ambiental.

\section{CONSIDERAÇÕES FINAIS}

O programa por possuir caráter educativo, social, científico e técnico permite alcançar um público variado e democratizar os conhecimentos na área ambiental, além de socializar os projetos da UNESP, valorizando a interação com a comunidade local.

Ainda, nesse encaminhamento, o Programa Olhar Ambiental pelos meios de mídia televisiva e pelo Blog contribui na socialização de conhecimentos na área ambiental, e também estimula os acadêmicos a participarem dessa discussão ambiental nos diversos segmentos, o que implica na formação desses profissionais que serão futuros 
Administradores por possibilitar um conhecimento mais abrangente nas áreas da gestão ambiental e jornalismo.

\section{REFERÊNCIAS}

BARROS, A. A. S. A televisão como mídia sócio-cultural. Disponível em: <http://www.cult.ufba.br/wordpress/24502.pdf>. Acesso em: 19 out. 2012.

BOFF, L. Saber cuidar: ética do humano: compaixão pela Terra. Petrópolis: Vozes, 1999.

CURADO, O. A notícia na TV: o dia-a-dia quem faz telejornalismo. São Paulo: Alegro, 2002.

TEODORO, C. et al. Mídia e meio ambiente. Disponível em: http://www.catolicato.edu.br/portal/portal/downloads/docs_gestaoambiental/projetos2010-1/1-Periodo/Midia_ e_meio_ambiente.pdf>. Acesso em: 19 out. 2012. 